\title{
Short Low Concentration Cisplatin Treatment Leads to an Epithelial Mesenchymal Transition-like Response in DU145 Prostate Cancer Cells
}

\author{
Yi-Qing Liu', Guo-An Zhang ${ }^{2}$, Bing-Chang Zhang ${ }^{1}$, Yong Wang ${ }^{1}$, Zheng Liu ${ }^{3}$, \\ Yu-Lian $\mathrm{Jiao}^{4}$, Ning Liu ${ }^{5 *}$, Yue-Ran $\mathrm{Zhao}^{4 *}$
}

\begin{abstract}
Background: Prostate cancer is one of the main causes of cancer death, and drug resistance is the leading reason for therapy failure. However, how this occurs is largely unknown. We therrfore aimed to study the response of DU145 cells to cisplatin. Materials and Methods: Du145 prostate cancer cells were treated with a low dose of cisplatin for $24 \mathrm{~h}$ and cell viability and number were determined by MTT assay and trypan blue exclusion assay, respectively. The real time polymerase chain reaction (PCR) was used to assess responses to cisplatin treatment. Results: After 24h $2 \mu \mathrm{g} / \mathrm{ml}$ treatment did not result in significant reduction in cell viability or number. However, it led to enhanced cancer cell invasiveness. E-cadherin mRNA was reduced, and vimentin, Snail, Slug, metalloproteinase 9 (MMP9) mRNA expression increased significantly, a feature of epithelial-mesenchymal transition (EMT). Conclusions: Short time low concentration cisplatin treatment leads to elevated invasiveness of DU145 cancer cells and this is possibly due to EMT.
\end{abstract}

Keywords: Epithelial-mesenchymal transition - prostate cancer - cisplatin - cancer invasiveness

Asian Pac J Cancer Prev, 16 (3), 1025-1028

\section{Introduction}

Prostate cancer is the second most frequently diagnosed cancer and the sixth leading cause of cancer death(Jemal et al., 2011). Its incidence is higher in developed countries, in America it is the most common cancer and is the second leading cause of cancer death in men (Siegel et al., 2014). In Asia, its incidence is relatively low, but shows a increasing trend (Jung et al., 2013; Du et al., 2014). Although multiple approaches has been used to treat this cancer, $10-25 \%$ prostate cancer patients still die of , mainly cancer metastasis (D'Amico et al., 2002).

Cisplatin is a commonly used chemotherapeutic drug for varied types of cancers including prostate cancer. It kills cancer cells by covalently binding to DNA and forming DNA adducts, which activates various signaltransduction pathways, such as DNA-damage recognition and repair, cell-cycle arrest, and programmed cell death/ apoptosis (Siddik, 2003; Kelland, 2007).

It has been reported that the residual ovarian cells that survived 3 or 5 days of cisplatin treatment display EMT and stem cell properties including increased invasiveness(Latifi et al., 2011; Baribeau et al., 2014), And the MAPK/ERK signaling pathway activation was reported to be one of the possible mechanisms underlying cisplatin's this effect (Baribeau et al., 2014). Similar to this study, Han and colleagues (Han et al., 2013; Han et al., 2014) showed that Gastric Cancer Cell that survived $48 \mathrm{~h}$ Doxorubicin treatment showed EMT, and this phenotype is maintained by those cancer cells, indicating an epigenetic mechanism may be responsible for the EMT.

Inspired by those studies, we wondered if short time (24h) low concentration $(2 \mu \mathrm{g} / \mathrm{ml})$ of cisplatin treatment leads to more malignant phenotype in vitro in DU145 cell line modal.

\section{Materials and Methods}

\section{Cell lines and reagents}

DU145 cells were maintained in DMEM supplemented with $10 \%$ fetal bovine serum (FBS), 100 units/ml penicillin and $0.1 \mathrm{mg} / \mathrm{ml}$ streptomycin. The cells were maintained at $37^{\circ} \mathrm{C}$ in a humidified incubator with $5 \%$ carbon dioxide. 3-[4, 5-Dimethylthiazol-2-yl]-2, 5-diphenyltetrazolium bromide (MTT), dimethylformamide, sodium dodecyl sulfate (SDS) and cisplatin were purchased from Sigma (Shanghai, China).

\section{3-[4,5-Dimethylthiazol-2-yl]-2,5-diphenyltetrazolium bromide (MTT) assay \\ MTT assay was based on the method by Hansen et al. (1989). Cell viability assays were carried out using}

${ }^{1}$ Department of Clinical Laboratory, ${ }^{3}$ Department of Urology, ${ }^{4}$ Department of Central Laboratory, Shandong Provincial Hospital affiliated to Shandong University, Shandong University, ${ }^{2}$ Department of The Morphology Laboratory, ${ }^{5}$ Department of Information Technology, Jining Medical University, Jining, China*For correspondence: yideyou9@163.com,yrzhao@sdu.edu.cn 


\section{Yi-Qing Liu et al}

the MTT dye conversion assay in 96-well plates. DU145 cells were planted into 96-well plates with a density of 4000 cells/well. After overnight, cells were treated with cisplatin-containing medium. $24 \mathrm{~h}$ later, MTT ( $25 \mu \mathrm{l}$ of 5 $\mathrm{mg} / \mathrm{ml}$ MTT in sterile PBS) was added to the medium and incubate for $2 \mathrm{~h}$ at $37^{\circ} \mathrm{C}$. The reaction was stopped, and the cells were lysed by the addition of $100 \mu$ lysis buffer consisting of $20 \%$ SDS in a water/dimethylformamide (1:1) solution ( $\mathrm{pH} 4.7)$. Cell lysates were placed at $37^{\circ} \mathrm{C}$ overnight to allow cell lysis and dye solubilization. The absorbance OD was read at $570 \mathrm{~nm}$ and $630 \mathrm{~nm}$ as reference using a Thermo MULTISKAN MK3 microplate reader. The absorbance of each well was calculated as $\mathrm{OD}_{570}-\mathrm{OD}_{630}$. MTT assays were carried out on three independent experiments, each performed in triplicate.

\section{Typan blue cell number counting}

Cells were planted in 24-well plates at a density of $1 \times 10^{5}$ cells/well. And after overnight, medium was changed into cisplatin-containing medium. 24h later, cells were collected by using trpsin-EDTA solution, and live cells are counted by the TC10 (Bio-Rad) cell counter using trypan blue exclusion test (Strober, 2001). Every group has 3 replicates and the assay was repeated 3 times.

\section{Scratch assay}

This assay was done using Ibidi Culture-Insert (Ibidi, Germany, No.80209). This approach provides two cell culture reservoirs with a separation wall of $500 \mu \mathrm{m}$ thick. The culture-Inserts were placed in the individual wells of 24-well plate, and $100 \mu \mathrm{l}$ of DMEM containing $3 \times 10^{4}$ cells was added into each insert. After overnight, the inserts were removed and scratch was created. The cells were washed by pre-warmed PBS and each well was filled with $1 \mathrm{ml}$ DMEM containing $2 \mu \mathrm{g} / \mathrm{ml}$ cisplatin, or DMEM alone as control. Then pictures were then taken as $0 \mathrm{~h}$, and 4 or $24 \mathrm{~h}$ later, pictures were taken again. The area of the wounds were determined by image J (http:// rsb.info.nih.gov) using the freehead selection mode. The migration of cells toward the wounds was expressed as percentage of wound closure:

$\%$ of wound closure $=\left[\left(\mathrm{at}={ }_{0 \mathrm{~h}}-\mathrm{at}={ }_{\Delta \mathrm{h}}\right) / \mathrm{at}={ }_{0 \mathrm{~h}}\right] \times 100 \%$, where at $=0 \mathrm{~h}$ is the area of wound measured immediately after scratching, and $a t={ }_{\Delta h}$ is the area of wound measured 4 or $24 \mathrm{~h}$ after scratching (Yue et al., 2010).

\section{RNA Isolation and cDNA Synthesis}

Total RNA was prepared using Trizol reagent (Invitrogen, USA) according to the instructions. Firststrand cDNAs were synthesized from $1 \mu \mathrm{g}$ DNaseItreated total RNA using a TIANGEN FastQuant RT Kit (with gDNase) (TIANGEN, China) according to the manufacturer's instructions.

\section{Real-Time PCR}

The expression of a set of gene transcripts was determined in triplicate with real-time polymerase chain reaction using SYBR Green PCR Master Mix(CWBIO, China). The primers for the set of mRNAs were summarized in Table 1. Each PCR reaction was carried out in a final volume of $20 \mu \mathrm{l}$ containing $10 \mu \mathrm{l}$ of $2 \times \mathrm{SYBR}$
Green Master Mix, $0.8 \mu \mathrm{l}$ of each $10 \mu \mathrm{M}$ forward and reverse primers and 8.2 $\mu \mathrm{l}$ DEPC treated water and $1 \mu \mathrm{l}$ cDNA. PCR amplification was performed in 40 cycles using the following sequence: $95^{\circ} \mathrm{C}$ for $10 \mathrm{~min}, 95^{\circ} \mathrm{C}$ for $15 \mathrm{sec}, 60^{\circ} \mathrm{C}$ for $1 \mathrm{~min}$. Data were normalized to GAPDH expression as housekeeping gene. LinRegPCR software (Ruijter et al., 2009) was used for quantification of expression, and mRNA expression fold change was calculated.

\section{Statistical analysis}

The absorbance value of MTT assay and the expression of the set of mRNA were expressed as mean \pm SD. ANOVA with Bonferroni post test was used to determine the difference among 3 or more groups while students' T-test was used to determine the difference between 2 groups.

\section{Results}

$2 \mu \mathrm{g} / \mathrm{ml}$ cisplatin treatment for $24 \mathrm{~h}$ does not lead to significantly reduced cell viability/ number.

DU145 cells were treated with 0 (as a control), 2, $10 \mu \mathrm{g} / \mathrm{ml}$ cisplatin for 1, 2 and 3 days. And MTT assay was used to assess the viability of each group. As shown in Fig 1A, $2 \mu \mathrm{g} / \mathrm{ml}$ cisplatin treatment for $24 \mathrm{~h}$ does not significantly decrease the viability compared with the control group, while all other treatment sharply reduced the viability of DU145 in a time- and dose-dependent manner. To confirm the effect of low concentration of cisplatin treatment on the cells, cells were planted in 24well plate and treated with $2 \mu \mathrm{g} / \mathrm{ml}$ cisplatin for $24 \mathrm{~h}$ and counted using TC10 (Bio-Rad) cell counter. It revealed no obvious difference between $2 \mu \mathrm{g} / \mathrm{ml}$ cisplatin treatment and control group (Figure 1B).

Cell invasiveness was enhanced by low concentration of cisplatin treatment.

It has been reported that cells surviving cisplatin treatment displayed increased migratory potential (Latifi et al., 2011). And we wanted to see whether low dose of cisplatin, which did not kill cells at $24 \mathrm{~h}$ time point, could leads to elevated invasiveness. Cell scratch assay showed that after $24 \mathrm{~h}$ of $2 \mu \mathrm{g} / \mathrm{ml}$ cisplatin treatment, the migratory ability was elevated. Actually, at as early as $4 \mathrm{~h}$ after cisplatin treatment, the difference between treatment
A

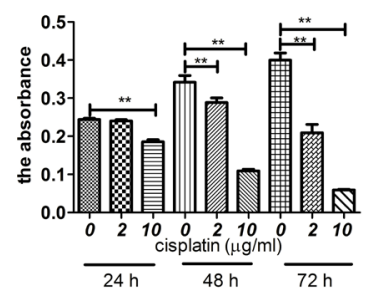

B

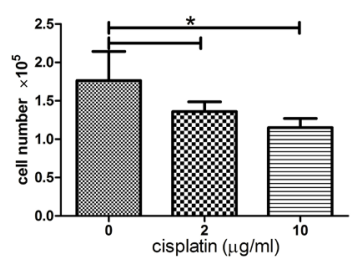

Figure 1. Low Concentration of Cisplatin Treatment for $24 \mathrm{~h}$ does not Reduce the Viability/Number Significantly. (A) Cell viability was assessed by MTT assay after treatment of 0,2 and $10 \mu \mathrm{g} / \mathrm{ml}$ cisplatin for 24,48 and 72h; (B) cells were treated with 0,2 and $10 \mu \mathrm{g} / \mathrm{ml}$ cisplatin for $24 \mathrm{~h}$ and cell number was determined by cell number counting. $* p<0.05 . * * p<0.01$ 


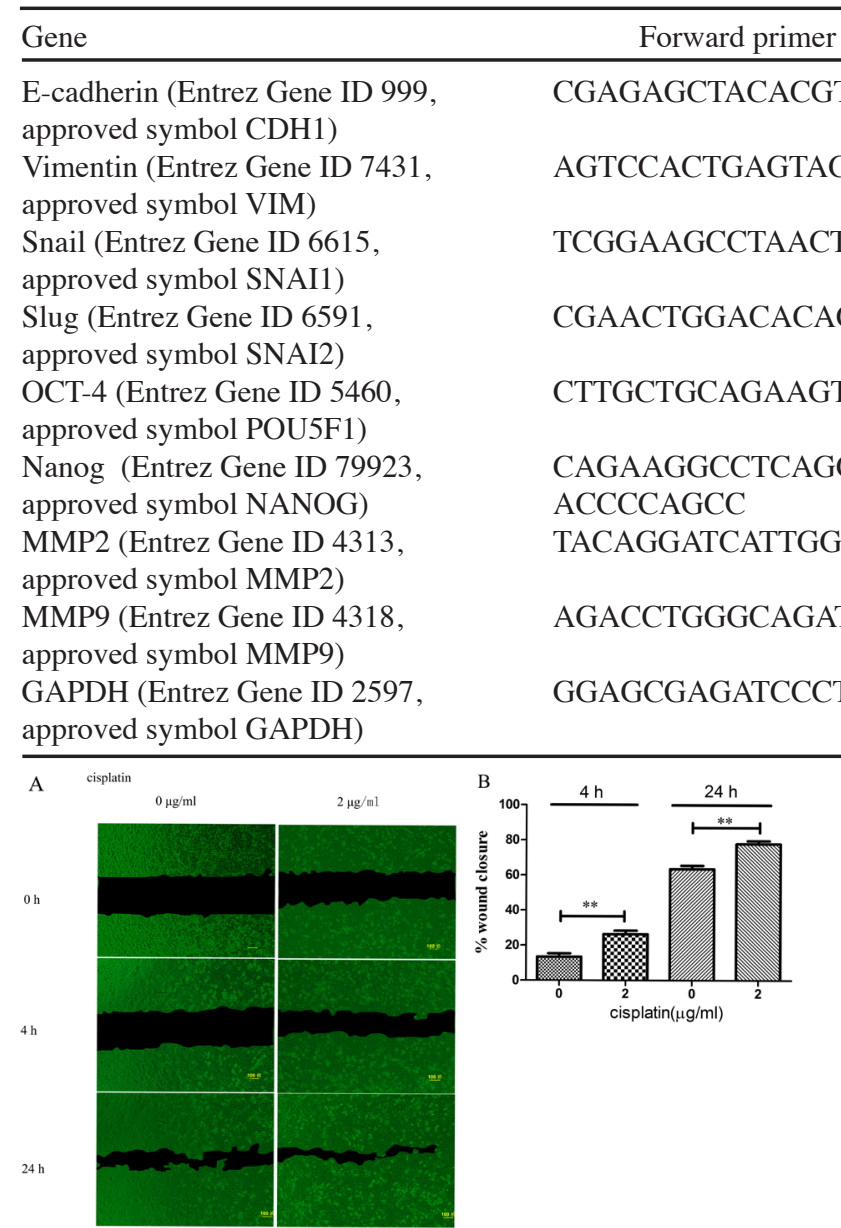

Figure 2. The Migratory Abilities of DU145 Cells in the Presence and Absence of Cisplatin Was Determined by Scratch Assay. (A) The phase contrast images of the assay. Bar: $100 \mu \mathrm{m}$; (B) The graphs represent percentage of wound closure from three independent experiments. ${ }^{* *} p<0.01$
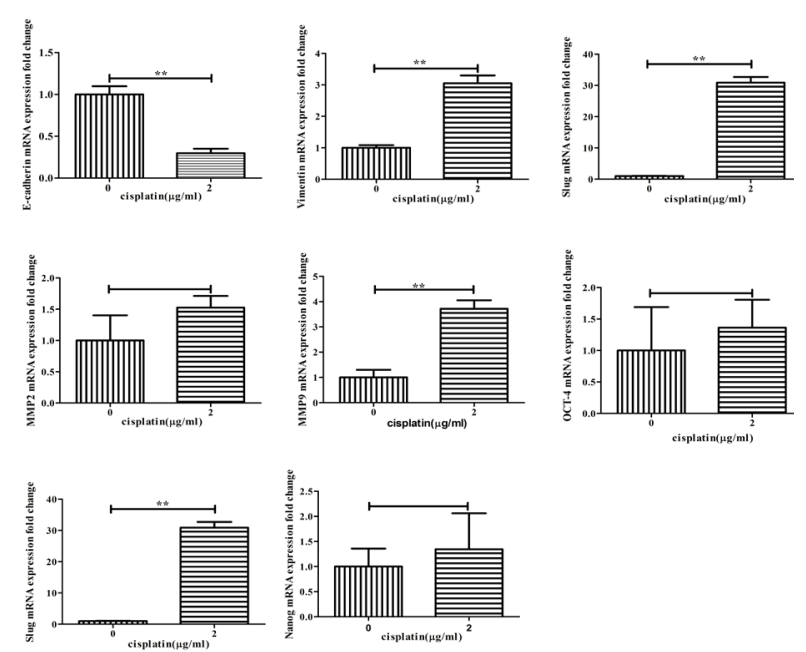

Figure 3. the EMT Markers mRNA Expression Change in Response to Cisplatin Treatment for 24h. ${ }^{* *} p<0.01$ group and control group is clear (Figure 2).

EMT markers $m R N A$ expression change in response to cisplatin.

It is now increasingly accepted that EMT confers invasive ability on cancer cells (Gavert and Ben-Ze'ev, 2008; Kalluri and Weinberg, 2009). So we determine
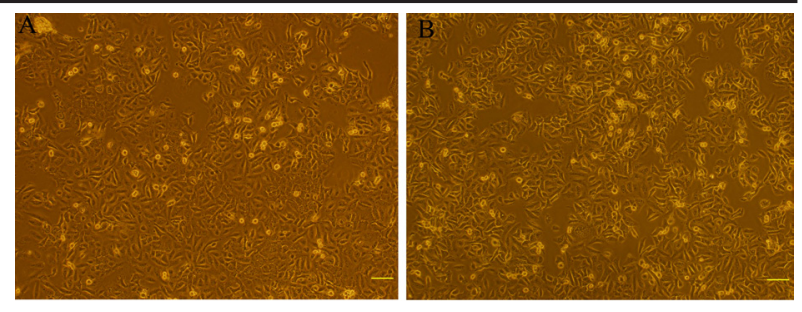

Figure 4. DU145 Cell Morphology Treated with 0 (A) and $2 \mu \mathrm{g} / \mathrm{ml}$ Cisplatin; (B) for $24 \mathrm{~h}$ Respectively. Scale bar, $100 \mu \mathrm{m}$

whether EMT occurred in the process of cisplatin-induced enhanced migration. The expression of EMT markers including E-cadherin, vimentin, Slug, Snail, Twist-1, OCT-4, metalloproteinase 2 (MMP2), and MMP9 were assessed by real time PCR. As Fig 3 showed, in response to treatment, the expression of E-cadherin mRNA reduced, while that of mRNA of vimentin, Snail, Slug, MMP9 increased significantly. Although MMP2, Nanog, OCT4 mRNA expression increased, the differences do not reach significance. Furthermore, no obvious change in morphology was observed in the cells treated with $2 \mu \mathrm{g} /$ $\mathrm{ml}$ cisplatin for 24h (Figure 4).

\section{Discussion}

Platinum complexes are clinically used as adjuvant therapy of cancers aiming to induce tumor cell death and combination-chemotherapy with cisplatin is a cornerstone for the treatment of multiple cancers (Florea and Busselberg, 2011). However, cancer relapses after initial tumor regression often occur, with cancer cells with more malignant phenotype such as resistant to the initial drugs and enhanced invasiveness. However, the detailed mechanisms underlying this phenomenon are not completed understood.

We hypotheses cancer cells' response to cisplatin may provide insights about the process of cisplatin-induced invasive phenotype. So we examined the response of Du145 cells to low concentration of cisplatin in $24 \mathrm{~h}$.

Our results showed that $24 \mathrm{~h}$ low concentration of cisplatin treatment did not reduce the viability/number of 


\section{Yi-Qing Liu et al}

DU145 cells obviously. However, it significantly increased the migratory ability of the cells as assessed by scratch assay. And similar to the increasingly accepted notion that EMT confer cancer cells invasive ability (Gavert and Ben-Ze'ev, 2008; Kalluri and Weinberg, 2009), our data showed some of the EMT markers' mRNA expression changed in the EMT-like way, such as E-cadherin, vimentin, Snail, Slug, and MMP2, while that of OCT-4, MMP9, and Nanog, did not increase that much. This observation was similar to the study of Lang et al (Lang et al., 2012) revealing that in response to heat shock for 30 min or less, cancer cells displayed increased migration with partial EMT.

In conclusion, our study showed that in response to cisplatin, DU145 cells displayed elevated migratory ability and an EMT-like phenotype. Disrupting this response may increase cisplatin's cancer-killing efficiency.

\section{References}

Baribeau S, Chaudhry P, Parent S, et al (2014). Resveratrol inhibits cisplatin-induced epithelial-to-mesenchymal transition in ovarian cancer cell lines. PLoS One, 9, 86987.

D'Amico AV, Cote K, Loffredo M, et al (2002). Determinants of prostate cancer-specific survival after radiation therapy for patients with clinically localized prostate cancer. J Clin Oncol, 20, 4567-73.

Du LB, Li HZ, Wang XH, et al (2014). Analysis of cancer incidence in Zhejiang cancer registry in China during 2000 to 2009. Asian Pac J Cancer Prev, 15, 5839-43.

Florea AM, Büsselberg D (2011). Cisplatin as an anti-tumor drug: cellular mechanisms of activity, drug resistance and induced side effects. Cancers (Basel), 3, 1351-71.

Gavert N, Ben-Ze'ev A (2008). Epithelial-mesenchymal transition and the invasive potential of tumors. Trends Molecular Medicine, 14, 199-209.

Han R-F, Ji X, Dong X-G, et al (2014). An epigenetic mechanism underlying doxorubicin induced EMT in the human BGC823 gastric cancer cell. Asian Pac J Cancer Prev, 15, 4271-4.

Han R, Xiong J, Xiao R, et al (2013). Activation of $\beta$-catenin signaling is critical for doxorubicin-induced epithelialmesenchymal transition in BGC-823 gastric cancer cell line. Tumor Biol, 34, 277-84.

Hansen MB, Nielsen SE, Berg K (1989). Re-examination and further development of a precise and rapid dye method for measuring cell growth/cell kill. J Immunological Methods, 119, 203-10.

Jemal A, Bray F, Center MM, et al (2011). Global cancer statistics. CA: Cancer J Clin, 61, 69-90.

Jung K-W, Won Y-J, Kong H-J, et al (2013). Cancer statistics in Korea: incidence, mortality, survival and prevalence in 2010. Cancer Res Treatment, 45, 1-14.

Kalluri R, Weinberg RA (2009). The basics of epithelialmesenchymal transition. J Clin Invest, 119, 1420-8.

Kelland L (2007). The resurgence of platinum-based cancer chemotherapy. Nat Rev Cancer, 7, 573-84.

Lang BJ, Nguyen L, Nguyen HC, et al (2012). Heat stress induces epithelial plasticity and cell migration independent of heat shock factor 1. Cell Stress Chaperones, 17, 765-78.

Latifi A, Abubaker K, Castrechini N, et al (2011). Cisplatin treatment of primary and metastatic epithelial ovarian carcinomas generates residual cells with mesenchymal stem cell-like profile. J Cell Biochem, 112, 2850-64.

Ruijter J, Ramakers C, Hoogaars W, et al (2009). Amplification efficiency: linking baseline and bias in the analysis of quantitative PCR data. Nucleic Acids Res, 37, 45

Siddik ZH (2003). Cisplatin: mode of cytotoxic action and molecular basis of resistance. Oncogene, 22, 7265-79.

Siegel R, Ma J, Zou Z, et al (2014). Cancer statistics, 2014. CA Cancer J Clin, 64, 9-29.

Strober W (2001). Trypan blue exclusion test of cell viability. Current protoc immunol, Appendix 3:Appendix 3B.

Yue PY, Leung EP, Mak NK, et al (2010). A simplified method for quantifying cell migration/wound healing in 96-well plates. J Biomol Screen, 15, 427-33. 